\title{
O PROCESSO DE ESCOLARIZAÇÃO NA 3ª IDADE: DESAFIOS DE UMA COMUNIDADE RURAL DA AMAZÔNIA
}

\section{ARTIGO ORIGINAL}

OLIVEIRA, Marcus Mustafa de ${ }^{1}$

OLIVEIRA, Marcus Mustafa de. 0 processo de escolarização na 3ª idade: Desafios de uma comunidade rural da Amazônia. Revista Científica Multidisciplinar Núcleo do Conhecimento. Ano 04, Ed. 07, Vol. 05, pp. 61-68. Julho de 2019. ISSN: 2448-0959

\section{RESUMO}

Na sociedade do conhecimento é urgente que sejam discutidos meios de democratizar o acesso aos estudos àqueles que nunca tiveram oportunidade, a continuidade que por motivos os mais diversos tiveram que interrompê-los e estimular os que se acham acomodados à situação de representarem mais um número nas estatísticas dos brasileiros não alfabetizados, situação estas vivenciadas por muitos idosos que moram nos ramais da BR 174. Por esse motivo essa pesquisa tem como objetivo trazer a problemática da EJA de alunos que no decorrer do ano desistem da escola por inúmeros motivos. Através de pesquisa bibliográfica em escola de comunidade onde o acesso é precário em época do inverno devido ao não acesso dos transportes escolares nos ramais dessa rodovia federal, essa pesquisa vem abordar essas dificuldades e outras, e, como conclusão um balanço do rendimento escola dos anos de 2016 e 2017.

Palavras-chaves: idoso, BR 174, ramais.

${ }^{1}$ Mestrando em Ciências da Educação, Saint Alcuim (2016- ), Especialização em Administração Escolar, Ucam (2006) Complementação Pedagógica em História, Fest (2005), Bacharelado em Teologia, Fatebov (2003). 


\section{INTRODUÇÃO}

Essa pesquisa se dará na Escola Municipal Solange Nascimento situada na BR 174, no componente EJA, onde se vem notando durante anos a evasão dos idosos nas salas de aula, buscando entender a problemática e procurar com outras metodologias sua Permanência no âmbito escolar.

O tema em discussão se reveste de fundamental importância porque embora o contingente de idosos no Brasil seja bastante expressivo, poucos olhares estão voltados às problemáticas que os envolvem direta ou indiretamente.

Fala-se com certa frequência que o idoso precisa exercer sua cidadania, participação, mas pouco se fala em capacitá-lo a exercê-las. É como anunciar um tesouro situado em algum ponto e esquecer ou propositalmente não informar as pistas, ou seja, os caminhos para alcançá-los ou encontrá-los.

O alfabetismo tem o poder de promover o progresso social e individual; seu pressuposto é a crença de que o alfabetismo tem, necessariamente, consequências positivas, e apenas positivas: sendo o uso das habilidades e conhecimentos de leitura e escrita necessária para "funcionar" adequadamente na sociedade, participar ativamente dela e realizar-se pessoalmente, o alfabetismo torna-se responsável pelo desenvolvimento cognitivo e econômico, pela mobilidade social, pelo progresso profissional, pela promoção da cidadania. (SOARES, 2004, p. 35)

Decorrido dez anos de aprovação da Política Nacional do Idoso, que já propunha a adequação de currículos, metodologias e material didático aos programas educacionais destinados a este seguimento, e três anos de aprovação da Política Municipal do Idoso, é importante analisarmos a implementação destas políticas na área educacional no município de Manaus, em termos de sua qualidade efetividade e alcance para a erradicação ou minimização do analfabetismo de idosos no município. 
Isso está ocorrendo? O Idoso está sendo assistido pela Educação Rural? Com o intuito de responder estes questionamentos será feito uma pesquisa bibliográfica para alcançar tais objetivos.

\section{JUSTIFICATIVA}

O envelhecimento da população mundial está ocorrendo sem precedentes na história. Estudiosos de vários ramos do conhecimento interessados pela temática apontam para esta direção. Segundo Berzins (2003, P.19) "estima-se que a população de idosos seja 629 milhões de pessoas com crescimento anual na taxa de $2 \%$, ritmo este consideravelmente mais alto em relação ao resto da população e três vezes mais do que há 50 anos" e que a população brasileira de idosos já supera 15 milhões de pessoas". A autora utiliza o censo de 2010 para mostrar que na distribuição da população idosa por estado, Os estados do Rio de Janeiro (10,7 \%) Rio Grande do Sul $(10,4 \%)$ e Paraíba $(10,1 \%)$, possuem o maior percentual de idosos e os estados do Amazonas (4,8 \%) Roraima e Amapá $(4,0 \%)$ o menor percentual. Ainda que o estado tenha esse referencial, enfrenta os mesmos problemas que outros estados com maior percentual de idosos. Analisar a temática proposta se reverte de fundamental importância, por vários motivos. Vejamos alguns:

a) Necessidade de se oportunizar ao idoso em plena era da informação, o acesso ao conhecimento e à educação voltada à cidadania, inclusive na área de informática como forma de integrá-lo ainda que virtualmente a grande parte do globo.

Berzins, (2003, P. 19) afirma que "apesar do avanço do crescimento que houve no percentual de idosos alfabetizados no país, em 2010 ainda existiam. No Brasil, 5,1 milhões de idosos analfabetos e $64,8 \%$ declararam que sabiam ler e escrever um simples bilhete." Bruno, em seu artigo "cidadania não tem idade" aponta para a necessidade de se promover a educação para a cidadania "superando a tendência de reduzi-la ao conhecimento dos direitos e deveres civis e políticos. A autora destaca a necessidade de se politizar o tema da velhice nestes termos: "a conquista de um novo lugar e significado na sociedade, bem como as marcas de uma nova presença no 
segmento que os idosos passam pelo exercício pleno da cidadania, exercício da dimensão do ser político do homem".

b) Necessidade de se analisar como a legislação pertinente ao acesso ou continuidade dos estudos pelos idosos está sendo implementada na cidade de Manaus. Segundo IBGE (2010) a população de idosos da cidade de Manaus quase que duplicou no período de 1970 a 2010. O índice que era de 3,4\% evoluiu para 6,04\%. Informações preliminares fornecidas pela SEMED, responsável pela implementação da Política Municipal do Idoso na área da educação dão conta de que em Manaus há oito grupos de idosos em atividades, com média de 15 alunos frequentando as aulas regularmente e oito grupos desativados. Estão estes grupos efetivamente contribuindo para mente o aluno motivado a continuar seus estudos e por consequência contribuir na erradicação ou diminuição do analfabetismo dos idosos?

c) Necessidade de se refletir sobre os fatores que contribuem contraria ou favoravelmente para este acesso ou continuidade dos estudos. A identificação dos fatores pode subsidiar os órgãos e instituições gestoras da política educacional para o idoso a buscar alternativas `à superação das mesmas. Em um aspecto os estudiosos do envelhecimento e profissionais envolvidos no atendimento ao idoso tem pensamentos convergentes: que idoso ativo na vida familiar, social, envolvido em atividades físicas e ocupacionais e estimulado a encontrar alternativas às suas próprias dificuldades está menos propenso a desenvolver precocemente doenças que a comentem com maior frequência esta faixa etária e a segrega da participação e do convívio social. Identificar e sugerir formas de enfrentamento dos fatores impeditivos da participação do público alvo desta pesquisa se constitui questão de vital importância. 


\section{OBJETIVOS}

- Geral

Mostrar através de pesquisa, a Educação dos Idosos na Zona Rural na BR 174 da cidade de Manaus: suas conquistas e dificuldades.

\section{- Específicos}

I. Analisar programas de alfabetização para idosos;

II. Desenvolver programas educativos e em especial utilizar os meios de comunicação, a fim de informar a população sobre o processo de envelhecimento;

III. Prover adequações nos currículos, as metodologias e outros materiais didáticos aos programas educacionais destinados aos idosos.

\section{PROCEDIMENTOS METODOLÓGICOS}

Para execução desta pesquisa será feito levantamento bibliográfico documental, levantamento de fontes primarias com observação direta e participante na escola para atingir os objetivos, entrevistas abertas com questionários pré elaborados, levantamento junto a SEMED de como está sendo tratada a questão da educação dos idosos nas comunidades rurais especificamente na BR174 e por fim o Rendimento Escolar dos alunos nos anos de 2016 e 2017.

\section{DESENVOLVIMENTO}

Essa pesquisa deverá mostrar como está a qualidade da educação dos Idosos na Zona Rural de Manaus, na BR 174. Não abordará a capacidade do educador, nem tampouco a pedagogia adotada pela Escola pesquisada, entre outras. 


\section{FUNDAMENTAÇÃO TEÓRICA}

Esta pesquisa será norteada por duas categorias analíticas, a saber: aprendizagem continuada e educação para a cidadania.

É fundamental que a sociedade comece a buscar o enfrentamento de seus preconceitos para com o idoso e o encontro de alternativas para que este segmento seja parte ativa e constitutiva desta realidade: que tenha oportunidade de explorar seu potencial de aprendizagem e que esta nova educação se revista de oportunidades para o exercício de sua cidadania.

A ênfase na construção do conhecimento uma reflexão sobre o ambiente da aprendizagem e seus componentes.

Segundo Valente (2000) a proposta de uma educação diferenciada da educação tradicional caracterizada por aulas expositivas que enfatizam o ato de ensinar como pôr ou colocar signo ou depositar informação, reter, prender.

Devemos criar ambientes de aprendizagem com atividades, objetos e materiais de suporte pedagógico impregnado de determinados conceitos ou estratégias de modos que aprendizes, interagindo com os objetos desenvolvendo as atividades possam construir conhecimentos relacionados com esses conceitos e estratégias. (VALENTE, 2001)

Estabelecer o desenvolvimento de um processo de aprendizado social na construção de novas formas de relação, contribuindo para a formação e a constituição como sujeitos sociais ativos. ( BRUNO, 2003).

De acordo com esse autor acima citado, é fundamental refletir com idoso sobre contemporaneidade, levando-o a perceber como um sujeito do tempo presente, com possibilidade e perspectivas de tempo futuro. Desperta-lo para a necessidade de construir um projeto de vida que lhe confira significado... a educação para a cidadania deve incentivar os sujeitos a conciliarem seus projetos coletivos, na construção do significado de algo maior. 
Isto é contribuir para a formação e a constituição de cidadãos como sujeitos sociais ativos como protagonistas que buscam a construção de sua própria história e que tem no outro ser social um companheiro de lutas e não alguém que o expropria de sua autonomia e capacidade de fazer escolhas.

\section{CRONOGRAMA DE ATIVIDADES}

\begin{tabular}{|l|l|}
\hline $\begin{array}{l}\text { Datas } \\
\text { Fevereiro de 2016 a } \\
\text { dezembro de 2017. }\end{array}$ & \begin{tabular}{l}
-Levantamento e revisão bibliográfica \\
\hline
\end{tabular} \\
\hline & $\begin{array}{l}\text {-Contatos institucionais para obtenção } \\
\text { de fontes. Elaboração e aplicação dos instrumentos } \\
\text { de coletas de dados. }\end{array}$ \\
\hline & -Análise e interpretação dos resultados, relatórios. \\
\hline
\end{tabular}

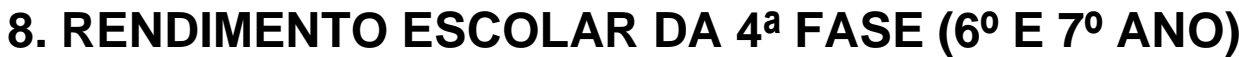

\begin{tabular}{|c|c|c|c|c|c|c|c|c|}
\hline $\begin{array}{l}\text { AN } \\
0\end{array}$ & $\begin{array}{l}\text { ENSI } \\
\text { NO }\end{array}$ & $\begin{array}{l}\text { SÉRI } \\
\text { E }\end{array}$ & TURNO & $\begin{array}{l}\text { TUR } \\
\text { MA }\end{array}$ & $\begin{array}{l}\text { MATRÍC } \\
\text { ULA } \\
\text { INICIAL }\end{array}$ & $\begin{array}{l}\text { DEIXOU } \\
\text { DE } \\
\text { FREQUEN } \\
\text { TAR }\end{array}$ & $\begin{array}{l}\text { TRANS } \\
\text { FE } \\
\text { RIDOS }\end{array}$ & $\begin{array}{l}\text { APR } \\
\text { O } \\
\text { VA } \\
\text { DOS }\end{array}$ \\
\hline $\begin{array}{l}201 \\
6\end{array}$ & $\begin{array}{l}\text { EJA- } \\
2 \stackrel{\circ}{ } \text { SE } \\
G\end{array}$ & $\begin{array}{l}4^{\underline{a}} \\
F A S \\
E\end{array}$ & $\begin{array}{l}\text { NOTUR } \\
\text { NO }\end{array}$ & A & 33 & 11 & 2 & 20 \\
\hline $\begin{array}{l}201 \\
6\end{array}$ & $\begin{array}{l}\text { EJA- } \\
2^{\circ} \text { SE } \\
G\end{array}$ & $\begin{array}{l}4^{a} \\
F A S \\
E\end{array}$ & $\begin{array}{l}\text { NOTUR } \\
\text { NO }\end{array}$ & B & 30 & 11 & 1 & 18 \\
\hline & & & & & $\begin{array}{l}\text { TOTAL: } \\
63\end{array}$ & 22 & 3 & 38 \\
\hline
\end{tabular}

Fonte: Sigeam 


\subsection{RENDIMENTO ESCOLAR DA 5ª FASE (8ํ E 9 ANO)}

\begin{tabular}{|c|c|c|c|c|c|c|c|c|}
\hline $\begin{array}{l}\text { AN } \\
\text { O }\end{array}$ & $\begin{array}{l}\text { ENSI } \\
\text { NO }\end{array}$ & $\begin{array}{l}\text { SÉRI } \\
\text { E }\end{array}$ & TURNO & $\begin{array}{l}\text { TUR } \\
\text { MA }\end{array}$ & $\begin{array}{l}\text { MATRÍC } \\
\text { ULA } \\
\text { INICIAL }\end{array}$ & $\begin{array}{l}\text { DEIXOU } \\
\text { DE } \\
\text { FREQUEN } \\
\text { TAR }\end{array}$ & $\begin{array}{l}\text { TRANS } \\
\text { FE } \\
\text { RIDOS }\end{array}$ & $\begin{array}{l}\text { APR } \\
\text { O } \\
\text { VA } \\
\text { DOS }\end{array}$ \\
\hline & $\begin{array}{l}\text { EJA- } \\
2^{o} \\
\text { SEG }\end{array}$ & $\begin{array}{l}5^{\underline{a}} \\
\text { FAS } \\
E\end{array}$ & $\begin{array}{l}\text { NOTUR } \\
\text { NO }\end{array}$ & U & 53 & 20 & 1 & 32 \\
\hline
\end{tabular}

Fonte: Sigeam

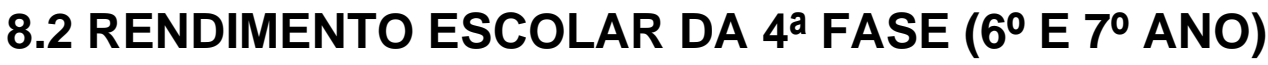

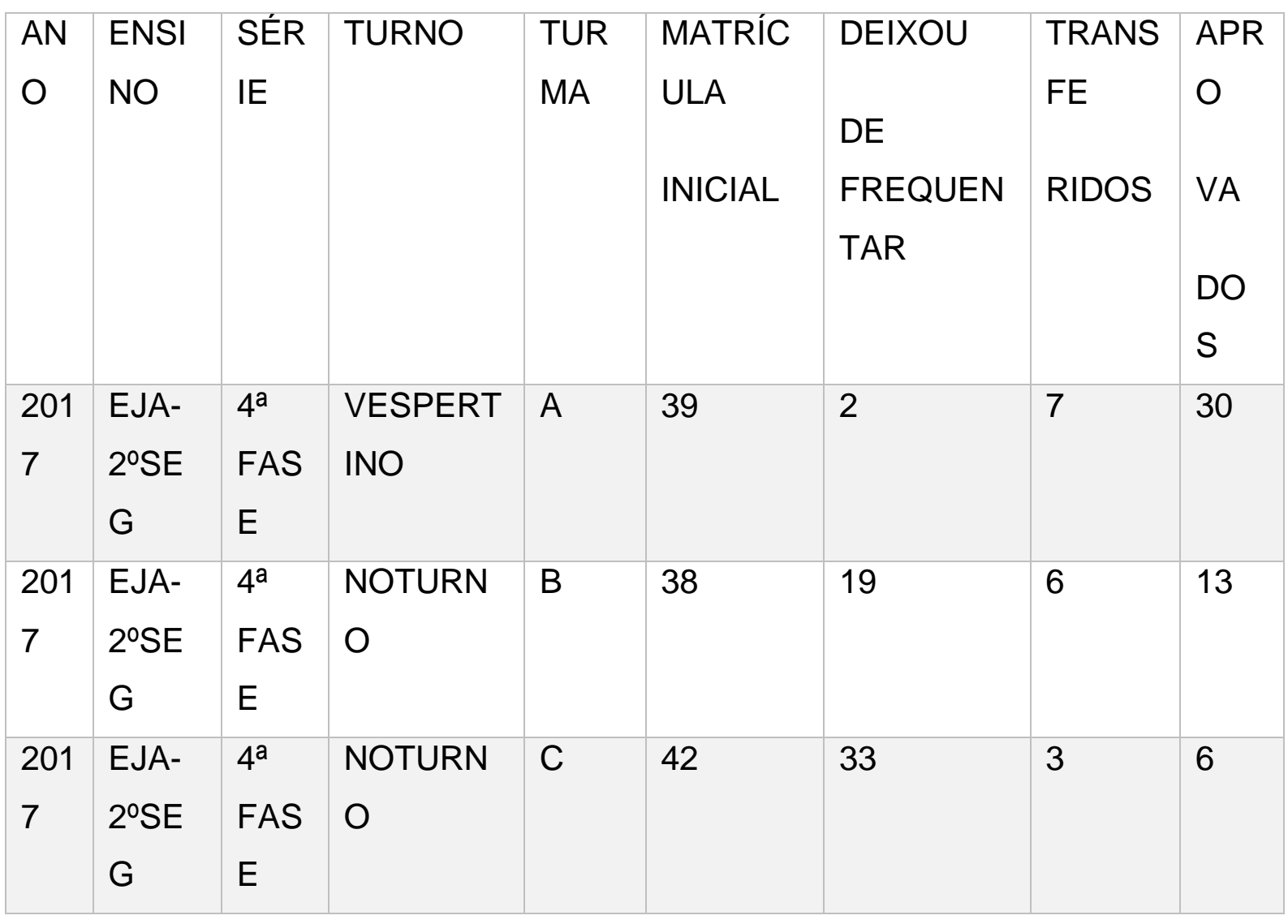




\begin{tabular}{|l|l|l|l|l|l|l|}
\hline & & TOTAL: & 54 & 16 & 49 \\
119 & & & \\
\hline
\end{tabular}

Fonte: Sigeam

\subsection{RENDIMENTO ESCOLAR DA 5ª FASE (8ํ E 9ํANO)}

\begin{tabular}{|c|c|c|c|c|c|c|c|c|}
\hline $\begin{array}{l}\text { AN } \\
0\end{array}$ & $\begin{array}{l}\text { ENSI } \\
\text { NO }\end{array}$ & $\begin{array}{l}\text { SÉRI } \\
\text { E }\end{array}$ & TURNO & $\begin{array}{l}\text { TUR } \\
\text { MA }\end{array}$ & $\begin{array}{l}\text { MATRÍC } \\
\text { ULA } \\
\text { INICIAL }\end{array}$ & $\begin{array}{l}\text { DEIXOU } \\
\text { DE } \\
\text { FREQUEN } \\
\text { TAR }\end{array}$ & $\begin{array}{l}\text { TRANS } \\
\text { FE } \\
\text { RIDOS }\end{array}$ & $\begin{array}{l}\text { APR } \\
\text { O } \\
\text { VA } \\
\text { DOS }\end{array}$ \\
\hline $\begin{array}{l}201 \\
7\end{array}$ & $\begin{array}{l}\text { EJA- } \\
2^{\circ S E} \\
\text { G }\end{array}$ & $\begin{array}{l}5^{\mathrm{a}} \\
\text { FAS } \\
\mathrm{E}\end{array}$ & $\begin{array}{l}\text { NOTUR } \\
\text { NO }\end{array}$ & $A$ & 48 & 17 & 2 & 29 \\
\hline \multirow[t]{2}{*}{$\begin{array}{l}201 \\
7\end{array}$} & 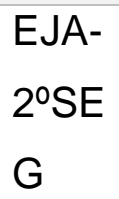 & $\begin{array}{l}5^{\mathrm{a}} \\
\text { FAS } \\
\mathrm{E}\end{array}$ & $\begin{array}{l}\text { NOTUR } \\
\text { NO }\end{array}$ & $B$ & 46 & 17 & 4 & 25 \\
\hline & & & & & $\begin{array}{l}\text { TOTAL: } \\
94\end{array}$ & 34 & 6 & 54 \\
\hline
\end{tabular}

Fonte: Sigeam

\section{CONCLUSÃO}

Analisando essa pesquisa que trata da educação dos Idosos na EJA, nota-se que o os alunos por serem mais velhos e por terem outros afazeres, desistem de seus sonhos que perseguem há anos. Desistem por não haver uma proposta pedagógica que os favorecessem em seus objetivos. Desistem por morar em ramais de difícil acesso. Desistem de sua única esperança que é a Educação para um futuro melhor. Futuro que ainda não os pertencem e, todos são brasileiros e, deveriam ser priorizados por sua escolha. Cerca de $30 \%$ a $60 \%$ não conclui a $5^{a}$ fase que irá dar o direito de adentrar na última etapa do Ensino Básico no Brasil, o Ensino Médio. 


\section{REFERÊNCIAS}

BERZINS, Marília Viana Anselmo da Silva. Envelhecimento populacional: uma conquista para ser celebrada. In: Revista Serviço Social \& Sociedade, Ano XXIV Especial 2003, Ed: Cortez, p 19-34

BRUNO, Marta Regina Pastor. Cidadania não tem idade. In. Revista Serviço Social \& Sociedade. Ano XXIV Especial 2003, Ed: Cortez, p 74-83

Instituto Brasileiro de Geografia e Estatística- IBGE- Censo Demográfico 2010.

SOARES, Magda. Alfabetização e Letramento: 2 ed. São Paulo: Contexto 2004.

VALENTE, José Armando. Aprendizagem continuada ao longo da vida - o exemplo da terceira idade. In: LONGEVIDADE: um novo desafio para a educação. Vitória Kachar (organizadora). 2001, Ed: Cortez, p 27-44

Enviado: Maio, 2019.

Aprovado: Julho, 2019. 